\title{
Current monitoring and innovative predictive modeling to improve care in the pediatric cardiac intensive care unit
}

\author{
Mary K. Olive, Gabe E. Owens \\ Division of Pediatric Cardiology, C.S. Mott Children's Hospital, University of Michigan, Ann Arbor, MI, USA \\ Contributions: (I) Conception and design: All authors; (II) Administrative support: All authors; (III) Provision of study materials or patients: All \\ authors; (IV) Collection and assembly of data: All authors; (V) Data analysis and interpretation: None; (VI) Manuscript writing: All authors; (VII) \\ Final approval of manuscript: All authors. \\ Correspondence to: Mary K. Olive, MD. 1540 East Medical Center Drive, Floor 11, Room 715-Z, Ann Arbor, MI 48109, USA. \\ Email: mkolive@med.umich.edu.
}

\begin{abstract}
The objectives of this review are (I) to describe the challenges associated with monitoring patients in the pediatric cardiac intensive care unit (PCICU) and (II) to discuss the use of innovative statistical and artificial intelligence (AI) software programs to attempt to predict significant clinical events. Patients cared for in the PCICU are clinically fragile and at risk for fatal decompensation. Current monitoring modalities are often ineffective, sometimes inaccurate, and fail to detect a deteriorating clinical status in a timely manner. Predictive models created by AI and machine learning may lead to earlier detection of patients at risk for clinical decompensation and thereby improve care for critically ill pediatric cardiac patients.
\end{abstract}

Keywords: Critical care; pediatric; cardiac intensive care; heart defects; congenital; decision support technologies

Submitted Apr 17, 2018. Accepted for publication Apr 20, 2018.

doi: $10.21037 /$ tp.2018.04.03

View this article at: http://dx.doi.org/10.21037/tp.2018.04.03

\section{Introduction}

A unique challenge exists in the visualization and interpretation of the enormous quantities of patient specific data in the extensively monitored environment of a pediatric cardiac intensive care unit (PCICU). PCICUs are specialized units with an immense range of pathologic diversity and complexity resulting partly from innovations and advancements in pediatric cardiac surgery and cardiopulmonary bypass. As staffing models evolve to meet the demands of this heterogeneous patient population the importance of accurate and reliable monitoring modalities in the PICICU becomes even more essential. The amount of data collected and stored has increased exponentially as more sophisticated monitoring devices are developed, however the number of measurements as well the inability to detect subtle physiologic changes impairs one's ability to identify patients in the early stages of hemodynamic or clinical deterioration. A benefit of electronically monitoring and storing large amounts of patient data is the ability to utilize that data to improve our understanding of pathologic processes and to develop predictive models to identify decompensating patients before devastating events occur. There is an opportunity to utilize big data to develop machine-learning algorithms that are predictive of certain clinical events. The development of statistical models and artificial intelligence (AI) to integrate physiologic, laboratory, and clinical data to predict patients who are progressing towards clinical decompensation has the potential to be transformative for cardiac intensive care medicine.

\section{Challenges of monitoring patients with congenital heart disease}

The physiology of patients with congenital or acquired heart disease presents challenges to conventional monitoring due to baseline abnormalities related to their underlying physiology, such as arterial hypoxemia, tachypnea, and tachycardia. Patients with systemic ventricular failure 
may initially have preserved arterial blood pressure due to systemic vasoconstriction from the activation of neurohormonal pathways that increase circulating catecholamines and aldosterone (1). Central venous pressure is affected by ventricular compliance and diastolic transmural pressure and is variable both following cardiac surgery and inherent to certain cardiac lesions (1). Oxygen consumption is frequently increased after congenital heart surgery, and patients may suffer from inadequate oxygen delivery despite relatively preserved cardiac output $(2,3)$. Patients with single ventricle physiology who have undergone stage I Norwood surgical palliation are some of the most challenging and tenuous patients in the PCICU. With shunt-dependent physiology, pulmonary and systemic circulations are parallel rather than in series, and the relative amounts of blood flow to the pulmonary and systemic circulations depend on the resistance within the vascular beds (4). Increased pulmonary blood flow occurs at the expense of systemic blood flow, and compensatory circulatory mechanisms that increase systemic vascular resistance further reduce systemic oxygen delivery (1). Patients with this physiology are at high risk for clinical decompensation, cardiac arrest (CA), and mortality $(5,6)$. Their unique physiology makes recognition of decompensation difficult to recognize with current monitoring modalities.

A state of decompensated shock occurs when oxygen delivery is inadequate to meet metabolic demands, resulting in anaerobic metabolism. Acidosis and end organ dysfunction begin to occur, and unless reversed, results in circulatory collapse. A core principle of intensive care medicine is the importance of monitoring patients to detect imbalances in the oxygen supply and demand relationship, and intervening prior to the development of decompensated shock (7). Interestingly, physician assessment of cardiac output based on physical exam findings poorly correlates with thermodilution calculated measurements $(8,9)$, highlighting the importance of objective and reliable monitoring modalities for both the detection of early pre-shock states, and for gauging the effectiveness of interventions. Central venous saturation monitoring with venous oximetry provides objective assessment of the adequacy of the oxygen supply-demand relationship (10), and goal directed therapy with monitoring of central venous saturations improves mortality in patients with septic shock $(11,12)$, and in stage I single ventricle patients $(13,14)$. Importantly, central venous saturation monitoring requires an indwelling central line that carries with it the risk of central line associated bacterial infections, and this risk is increased with longer duration of the line (15). Near-infrared spectroscopy (NIRS) provides non-invasive estimation of regional venous oxygen saturations, and is also a measure of the adequacy of oxygen-transport balance. The use of NIRS has gained popularity in PCICUs and prior studies have found good correlation between cerebral NIRS and jugular venous saturations in infants with congenital heart disease (16-18), however, measurements are fairly imprecise, and validation of this technology remains limited by the absence of absolute values for certain patient populations (19). In addition, NIRS is affected by factors such as skin pigmentation, patient age, hemoglobin concentration, and location of the sensor $(20,21)$. In all, current monitoring modalities for patients cared for in the PCICU are limited by the risks of obtaining and maintaining invasive monitoring devices and the lack of a true gold standard for some non-invasive modalities.

The prevalence of $\mathrm{CA}$ in hospitalized children is 0.77 per 1,000 admissions (22), and the relative incidence is higher in children with cardiac disease (23). Although these events are rare they consume a large proportion of medical costs, therapies, and morbidity $(6,23-25)$. The rate of CA following pediatric cardiac surgery is variable among centers, but has been reported to occur in $2.6-6 \%$ of patient encounters, and is associated with significantly higher mortality regardless of complexity of surgery $(6,25-27)$. Neonates, premature infants, and those undergoing the highest complexity surgeries, in particular stage I palliation for single ventricle lesions, represent some of the highest risk post-operative cohorts in the PCICU for CA (6). Patients with medical cardiac disease, such as acquired cardiomyopathies and myocarditis, also have a significant risk of CA and have worse survival compared to post-operative patients $(5,6,28)$. The extent to which CA is preventable is unclear, but studies have identified that physiologic features and signs are present prior to clinical decompensation, although sometimes either not identified or inadequately communicated between nurses and physicians (29). This phenomenon also applies to hospitalized patients with congenital heart disease (30). Since the rate of CA across PCICUs is variable and not associated with center surgical volume (25), there are likely strategies that would be effective at reducing the overall incidence of CA in patients with cardiac heart disease (6). In addition to provider-influenced strategies, the development of intelligent monitoring systems that aggregate physiologic and laboratory data to detect subacute stages of clinical decompensation and CA would be immensely beneficial in 
PCICUs. Monitoring systems that could not only identify current abnormalities of physiology, but could predict which patients are at risk for a clinical decompensation could revolutionize critical care medicine.

\section{Current monitoring and the trouble with false alarms}

Physicians and nurses working in intensive care units utilize continuous and intermittently monitored data to make high priority decisions. One study in an adult medical intensive care unit found that nurses, physicians, and other medical personal performed over 150 actions per patient per day, and that severe errors occurred on average two times per day (31). These findings highlight the importance of attention, focus, and experience for care providers practicing in critical care environments (32). Prior studies have demonstrated that a large percentage of alarms that occur in intensive care units are either inaccurate or clinically irrelevant (33-35). Clinically irrelevant alarms are technically correct, but are irrelevant in that they are reflective of a normal physiologic response, such as tachycardia during a stimulating intervention. A large percentage of false positive and irrelevant alarms lead to desensitization and alarm fatigue for providers, raising concern that an important alarm may be ignored (36). In a pediatric intensive care unit, one study found that nurse response time to potentially critical alarms increased significantly as the frequency of non-actionable alarms in the preceding 2 hours increased (35). Frequent alarms also place physiologic and emotional stress on care providers (37).

Most alarms are designed to create an audible signal after a simple numeric threshold is crossed, but this method is insufficient to interpret typical variation and interactions between components that occurs in a complex biological system (38). Biological systems are non-linear, they are composed of multiple components which interact together, and their behavior cannot be understood by analyzing the components individually, nor as a simple sum or multiple of the inputs to the system (38-40). New approaches to improving the accuracy of alarms have identified features or transformations of raw data that help determine the clinical importance of the alarm (38). Some of these approaches are relatively simple algorithms that filter the data to remove transient variations unlikely to be clinically relevant $(41,42)$. Other approaches use more than one signal source to evaluate a physiologic variable, such as using the electrocardiogram and the arterial pulse wave to determine the correct pulse rate (42). Furthermore, for even more complex processes, AI systems can utilize data sets to train an adaptive algorithm (38). There are also machine learning approaches aimed at developing intelligent alarms that utilize knowledge based approaches and rule based systems to develop explicit clinical decision trees (42). Decision tree induction can be used to integrate multiple different physiologic signals to distinguish true values from artifacts in monitored data (43). More sophisticated systems may move beyond improving alarm accuracy to actually identify statistical relationships within data sets for the prediction of various outcomes.

\section{Predicting risk}

Predictive monitoring systems would attempt to identify changing physiology or patient decompensations prior to obvious signs. Pediatric early warning scores (PEWS) have been implemented by many hospitals to identify deteriorating patients on the inpatient ward in a timelier manner to prevent severe deterioration or an urgent transfer to a higher level of care (44). These scoring systems are estimates of acuity reflective of abnormalities in vital signs and physical exam findings; and have escalation algorithms or interventions based on cutoff scores (44). The cardiac children's early warning score (C-CHEWS) was created specific to children with cardiac disease and is more sensitive and specific with for identification of patient who may experience an arrest or unplanned transfer to the ICU compared to PEWS (30). Published reports of the effectiveness of these score-based acuity models have shown variable sensitivity, specificity, and positive predictive value, which may be partially influenced by variability of implementation and cutoff values between hospitals (44). While PEWS and other early warning scores are fairly sensitive and specific in their identification of clinical decompensation or mortality, they often have relatively low positive predictive values, and thus over-identify patients, making their overall impact on resource utilization less clear (45). There are additional scoring indices that have also been developed to predict mortality for intensive care patients, such as the PRISM-IV for physiologic instability and mortality risk for patients in pediatric intensive care units (46), and the PICSIM score, a post-surgical mortality risk index tool for patients in the PCICU (47). Table 1 summarizes many of these score-based acuity models and recent publications regarding their effectiveness.

While these models can be useful as risk adjustment 
Table 1 Studies evaluating the performance of score based predictive models

\begin{tabular}{|c|c|c|c|c|c|}
\hline Score evaluated & Population & Study design & Components & $\begin{array}{l}\text { Outcome } \\
\text { predicted }\end{array}$ & $\begin{array}{l}\text { Statistical measures } \\
\text { of effectiveness }\end{array}$ \\
\hline $\begin{array}{l}\text { Bedside paediatric } \\
\text { early warning score } \\
\text { (PEWS) (48) }\end{array}$ & $\begin{array}{l}\text { Hospitalized } \\
\text { pediatric patients }\end{array}$ & Case control & $\begin{array}{l}7 \text { item scoring system: } \mathrm{HR}, \mathrm{RR} \text {, } \\
\text { respiratory effort, } \mathrm{O}_{2} \text { therapy, } \\
\text { temperature, SBP, CRT }\end{array}$ & $\begin{array}{l}\text { Urgent } \\
\text { admission to } \\
\text { the PICU }\end{array}$ & 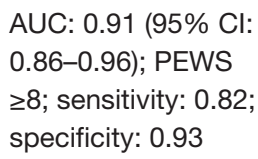 \\
\hline $\begin{array}{l}\text { Cardiac children's } \\
\text { early warning score } \\
\text { (C-CHEWS) (30) }\end{array}$ & $\begin{array}{l}\text { Inpatient cardiac } \\
\text { unit, patients who } \\
\text { experienced arrest } \\
\text { or unplanned } \\
\text { PCICU transfer }\end{array}$ & $\begin{array}{l}\text { Retrospective } \\
\text { cohort study }\end{array}$ & $\begin{array}{l}\text { Nursing administered score } \\
\text { based on CNS, CV, respiratory } \\
\text { status, family and nursing } \\
\text { concern }\end{array}$ & $\begin{array}{l}\text { Cardiac arrest } \\
\text { or unplanned } \\
\text { transfer to the } \\
\text { PICU }\end{array}$ & $\begin{array}{l}\text { Score >3, AUC } \\
0.858 \text {; sensitivity: } \\
0.953 \text {; specificity: } \\
0.762 ; \text { PPV: } 0.508 ; \\
\text { NPV: } 0.984\end{array}$ \\
\hline $\begin{array}{l}\text { Pediatric index } \\
\text { cardiac surgical } \\
\text { intensive care } \\
\text { mortality (PICSM) } \\
(47)\end{array}$ & $\begin{array}{l}\text { Pediatric cardiac } \\
\text { surgical patients } \\
\text { admitted to the } \\
\text { PICU or PCICU }\end{array}$ & $\begin{array}{l}\text { Prospective } \\
\text { cohort study }\end{array}$ & $\begin{array}{l}\text { Multivariate logistic regression } \\
\text { including physiologic, } \\
\text { anatomic, and procedural } \\
\text { variables }\end{array}$ & Mortality & AUC: 0.87 \\
\hline $\begin{array}{l}\text { Score for neonatal } \\
\text { acute physiology } \\
\text { (SNAP-II) (51) }\end{array}$ & $\begin{array}{l}\text { Extremely preterm } \\
\text { infants }\end{array}$ & $\begin{array}{l}\text { Retrospective } \\
\text { cohort study }\end{array}$ & $\begin{array}{l}6 \text { components measured in } \\
\text { first } 12 \text { hours of life, lowest } \mathrm{BP} \text {, } \\
\text { lowest } \mathrm{pH} \text {, lowest temperature, } \\
\text { seizures, } \mathrm{UOP}, \mathrm{PaO}_{2} / \mathrm{FiO}_{2}\end{array}$ & $\begin{array}{l}\text { Mortality and } \\
\text { morbidity }\end{array}$ & $\begin{array}{l}\text { AUC: } 0.69(95 \% \mathrm{Cl}: \\
0.68-0.70)\end{array}$ \\
\hline
\end{tabular}

HR, heart rate; RR, respiratory rate; SBP, systolic blood pressure; CRT, capillary refill time; CNS, central nervous system; CV, cardiovascular; PCICU, pediatric cardiac intensive care unit; PICU, pediatric intensive care unit; AUC, area under the receiver operating curve; Cl, confidence interval; PPV, positive predictive value; NPV, negative predictive value; UOP, urine output.

tools for comparing clinical outcomes, they are based on population data rather than patient specific data, and they do not provide real time outcome predictions for individual patients. Therefore, there is a need for the development of data analytic technology to provide patient specific, real time prediction of outcomes. Data analytic technology can also be applied to detect potentially catastrophic illness in a subacute phase. Advanced technologies using statistical methods and AI can be used to develop predictive models by detecting patterns in electronically recorded data that are more significant than the raw data itself. While a multivariate regression analysis may identify single vital signs parameters that are predictors of decompensation, predictive models incorporate many physiologic vital signs to contrast normal physiology to physiology that is displayed prior to the event of interest, such as a clinical decompensation (52) or sepsis (53).
In 2001 Griffin and colleagues showed that infants in neonatal intensive care units who developed sepsis demonstrated a loss of heart rate variability hours prior to other clinical signs of deterioration $(53,54)$. This information led to the subsequent development of a predictive model that identified changes in heart rate characteristics suggestive of sepsis in infants prior to the development of obvious signs and symptoms (55). A randomized controlled trial demonstrated a significant reduction in mortality due to sepsis in low birthweight infants monitored with this predictive system $(53,56)$. The use of predictive models to develop a risk index was applied to patients with congenital heart disease by Rusin and colleagues (52). High resolution continuous physiologic data from single ventricle patients with parallel circulations was utilized to build a classification model based on differences in physiology between patients nearing 
a clinical decompensation compared to stable patients. As the goal of this model was to detect deterioration before obvious clinical signs developed, the hour of data immediately preceding the deterioration was not used in the classification model, as it is generally expected that obvious clinical signs of deterioration were present at that time (52). A risk index was created that measures similarity between a patients' current physiology and the physiology that was observed in infants who were approaching a clinical decompensation (52). This process is unique and beneficial in its ability to continuously and in real-time calculate the risk of deterioration for a certain patient. This study also indicates the ability of predictive models to discriminate the minor physiologic differences that are present in predecompensation periods, such as alterations in ST segment variability, which is a variable that is not easily evaluated from most bedside monitoring equipment (52). Although data was collected prospectively, the model was created retrospectively, therefore it is difficult to determine when clinicians recognized deteriorating patients and responded with interventions, such as non-invasive positive pressure ventilation or escalation of inotropic support (52). Another novel aspect of this study was the development of a predictive index for a specific patient population and physiology, raising the possibility of creating various other prediction models applicable to other physiologic states.

A new patient monitoring technology that incorporates high fidelity continuous data streaming into a model-based risk assessment to predict the development of inadequate oxygen delivery has the potential to improve clinicians' ability to identify early stages of clinical deterioration (32). This system incorporates many continuous and intermittently recorded hemodynamic variables and quantifies the likelihood that a patient is suffering from inadequate oxygen delivery, resulting in anaerobic metabolism (32). When the predictive index was compared to measured central venous saturations less than $40 \%$, which indicate anaerobic metabolism, the area under the receiver operating curve was 0.79 , supporting the correlation between continuously measured risk of inadequate oxygen delivery and intermittently measured values (32). Figure 1 is one example of a data aggregation and visualization software system that incorporates a predictive risk index to identify clinical deterioration earlier.

Large datasets are available from the electronically recorded continuously and intermittently monitored variables for patients in the intensive care unit, and while data driven analytic processes can be utilized to extract relevant knowledge and optimize clinical decisions, the unique properties of these data sets present significant challenges (57). Among these challenges are the heterogeneity of data, due to the large number and the variety of measured endpoints, heterogeneity of patients, and time asynchrony of measured values. Through the processes of data characterization, pre-processing, feature extraction, and feature selection, a predictive model for intensive care unit mortality was developed, and when applied to a post-surgical ICU data set, this predictive model outperformed transitional models of mortality risk prediction for ICU patients (57). This successful application of data driven analytics to outcome prediction is encouraging for the development of additional models that will aid physicians in extracting useful information for clinical decision making.

Machine learning and AI techniques can also be developed for risk prediction in intensive care units. Neural networks are machine learning algorithms that have the ability to learn input and output relationships from training sets of data; such as patterns of vital signs and laboratory findings that indicate a stable patient versus a decompensating patient (42). A neural network model was built using vital signs and laboratory data of patients admitted to a medical ward with hematologic malignancies, and then used to predict clinical decompensations, with excellent sensitivity and improved positive predictive value compared to other commonly used predictive scores of decompensation (58). Decision tree classification is another $\mathrm{AI}$ method for predicting risk of certain events, utilizing logistic regression models to determine important variables, which are then used as inputs for a machine learning based patient specific algorithm to evaluate the risk that a specific event or outcome occurs (59). This has been shown to be successful in determining infants who develop periventricular leukomalacia following cardiovascular surgery $(60,61)$. Jalali and colleagues developed a clinical decision support system for the prediction of mortality in an adult intensive care unit, creating a classification model from multiple physiologic, hemodynamic, and demographic variables that predicted in-hospital mortality more accurately than several acuity based scoring systems (59). Expert physiologic knowledge to group the various hemodynamic and laboratory data based on organ system was critical to the development and accuracy of this system, and highlights the importance of clinical expertise in the development of data-driven analytic models (59). While these studies, and others described in Table 2, are 


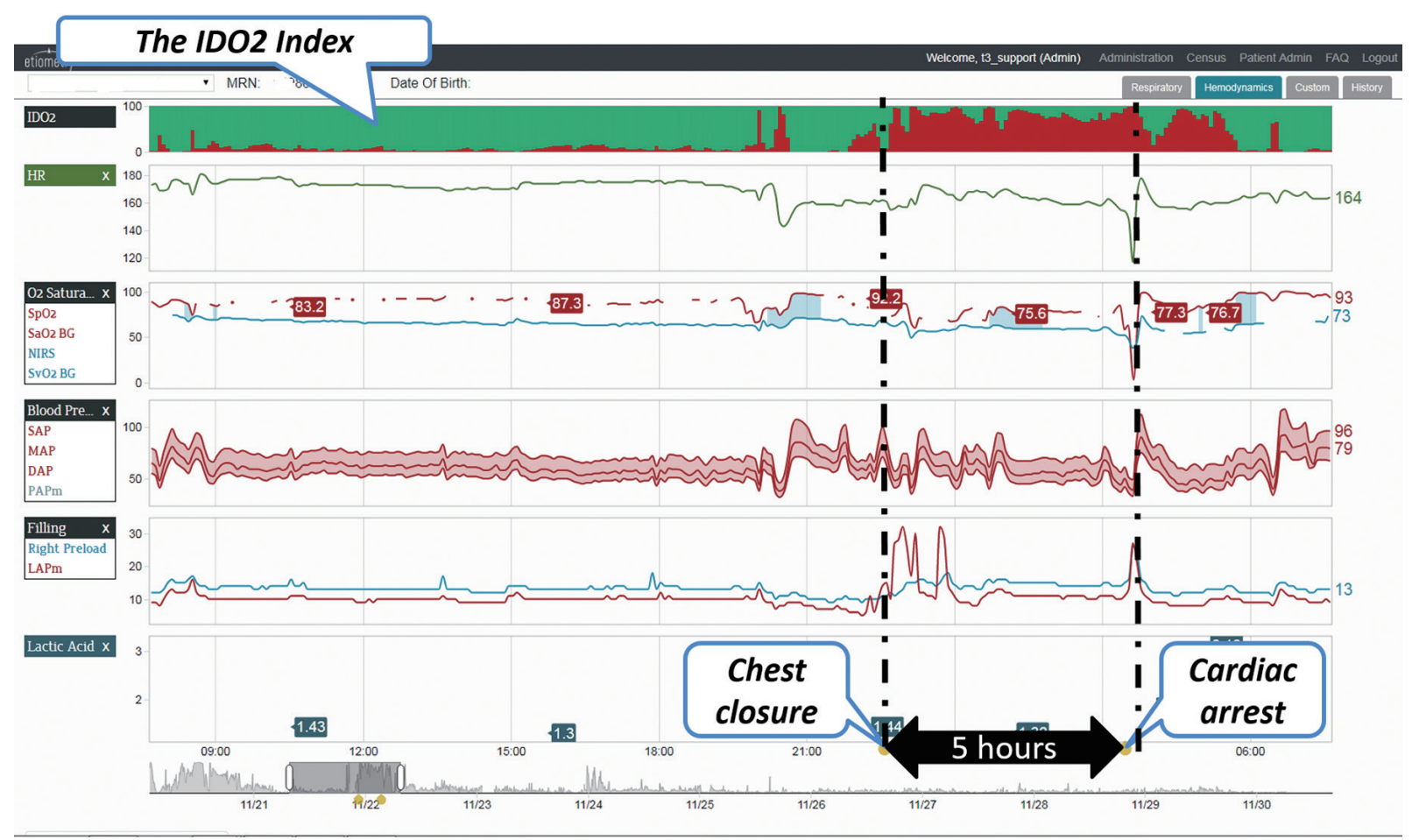

Figure 1 An example of one software technology that records, integrates, and visually displays patient data from multiple different sources and also creates a risk index (IDO2 index) to predict the likelihood of inadequate oxygen delivery, which is a precursor of anaerobic metabolism. In this example, the risk index increased substantially in the 5 hours prior to cardiac arrest, without significant changes in other vital signs.

Table 2 Studies of data-analytic models for prediction of outcomes

\begin{tabular}{|c|c|c|c|c|c|}
\hline Study & Patient population & Technology used & Study design & Endpoint predicted & Validity \\
\hline $\begin{array}{l}\text { Moorman } \\
\text { et al. (56) }\end{array}$ & $\begin{array}{l}\text { Neonatal intensive } \\
\text { care unit }\end{array}$ & $\begin{array}{l}\text { Heart rate } \\
\text { characteristic index }\end{array}$ & $\begin{array}{l}\text { Randomized } \\
\text { controlled trial }\end{array}$ & $\begin{array}{l}\text { Fold-increase in risk of } \\
\text { sepsis }\end{array}$ & $\begin{array}{l}\mathrm{HR} 0.78 \text { (95\% Cl: } \\
0.61-0.99) \text { for neonates } \\
\text { monitored with HRC }\end{array}$ \\
\hline $\begin{array}{l}\mathrm{Hu} \\
\text { et al. (58) }\end{array}$ & $\begin{array}{l}\text { Adult patients } \\
\text { with hematologic } \\
\text { malignancies }\end{array}$ & $\begin{array}{l}\text { Advanced neural } \\
\text { network }\end{array}$ & $\begin{array}{l}\text { Retrospective } \\
\text { cohort }\end{array}$ & $\begin{array}{l}\text { ICU transfer and cardiac } \\
\text { arrest }\end{array}$ & $\begin{array}{l}\text { Sensitivity: 0.93; } \\
\text { specificity: 0.97; PPV: } \\
0.78 \text {; NPV: } 0.99\end{array}$ \\
\hline
\end{tabular}

$\mathrm{SVO}_{2}$, central venous saturation; AUC, area under the receiver operating curve; CI, confidence interval; PPV, positive predictive value; NPV, negative predictive value; CPR, cardiopulmonary resuscitation. 
encouraging for future developments, to date, there are no validated or operationalized AI or machine learning techniques deployed in the PCICU population.

\section{Summary and conclusions}

Patients in the PCICU are at risk for CA and clinical decompensation, and earlier intervention in their course is likely to improve outcomes and prevent end organ dysfunction. Current monitoring modalities are sometimes ineffective for early identification of patients who are beginning to decompensate. Several technological advances have the potential to improve our ability to detect abnormal physiology more accurately and expediently. Mathematical models that analyze continuously recorded physiologic parameters to discriminate patterns of data, as well as machine learning and AI methods, are all promising for the development of outcome prediction for patients in the PCICU. As this technology is advanced it is important to continue to determining appropriate endpoints, as predictive systems are only as good as the outcome they predict. These advanced monitoring systems will continue to require clinicians to provide biological plausibility and to incorporate risk indices with other clinical data to determine the appropriate treatment approach. Machine learning may be able to predict the likelihood that something will happen, but it will not replace the judgment of clinicians to provide the appropriate therapy in the context of the clinical scenario to avoid a clinical decompensation.

\section{Acknowledgements}

None.

\section{Footnote}

Conflicts of Interest: The authors have no conflicts of interest to declare.

\section{References}

1. Bronicki RA, Chang AC. Management of the postoperative pediatric cardiac surgical patient. Crit Care Med 2011;39:1974-84.

2. Li J, Schulze-Neick I, Lincoln C, et al. Oxygen consumption after cardiopulmonary bypass surgery in children: determinants and implications. J Thorac Cardiovasc Surg 2000;119:525-33.
3. Li J, Zhang G, Holtby HM, et al. Inclusion of oxygen consumption improves the accuracy of arterial and venous oxygen saturation interpretation after the Norwood procedure. J Thorac Cardiovasc Surg 2006;131:1099-107.

4. Schwartz SM, Dent CL, Musa NL, et al. Single-ventricle physiology. Critical Care Clinics 2003;19:393-411.

5. Lowry AW, Knudson JD, Cabrera AG, et al. Cardiopulmonary resuscitation in hospitalized children with cardiovascular disease: estimated prevalence and outcomes from the kids' inpatient database. Pediatr Crit Care Med 2013;14:248-55.

6. Alten JA, Klugman D, Raymond TT, et al. Epidemiology and Outcomes of Cardiac Arrest in Pediatric Cardiac ICUs. Pediatr Crit Care Med 2017;18:935-43.

7. Checchia PA, Laussen PC. The cardiac intensive care unit perspective on hemodynamic monitoring of oxygen transport balance. Pediatr Crit Care Med 2011;12:S69-71.

8. Egan JR, Festa M, Cole AD, et al. Clinical assessment of cardiac performance in infants and children following cardiac surgery. Intensive Care Med 2005;31:568-73.

9. Tibby SM, Hatherill M, Marsh MJ, et al. Clinicians' abilities to estimate cardiac index in ventilated children and infants. Arch Dis Child 1997;77:516-8.

10. Bronicki RA. Venous oximetry and the assessment of oxygen transport balance. Pediatr Crit Care Med 2011;12:S21-6.

11. Rivers E, Nguyen B, Havstad S, et al. Early goal-directed therapy in the treatment of severe sepsis and septic shock. N Engl J Med 2001;345:1368-77.

12. de Oliveira CF, de Oliveira DS, Gottschald AFC, et al. ACCM/PALS haemodynamic support guidelines for paediatric septic shock: an outcomes comparison with and without monitoring central venous oxygen saturation. Intensive Care Med 2008;34:1065-75.

13. Tweddell JS, Hoffman GM, Mussatto KA, et al. Improved survival of patients undergoing palliation of hypoplastic left heart syndrome: lessons learned from 115 consecutive patients. Circulation 2002;106:I82-9.

14. Tweddell JS, Ghanayem NS, Mussatto KA, et al. Mixed venous oxygen saturation monitoring after stage 1 palliation for hypoplastic left heart syndrome. Ann Thorac Surg 2007;84:1301-10; discussion 1310-1.

15. Costello JM, Graham DA, Morrow DF, et al. Risk factors for surgical site infection after cardiac surgery in children. Ann Thorac Surg 2010;89:1833-41; discussion 1841-2.

16. Abdul-Khaliq H, Troitzsch D, Berger F, et al. Regional transcranial oximetry with near infrared spectroscopy (NIRS) in comparison with measuring oxygen saturation 
in the jugular bulb in infants and children for monitoring cerebral oxygenation. Biomed Tech (Berl) 2000;45:328-32.

17. Nagdyman N, Fleck T, Schubert S, et al. Comparison between cerebral tissue oxygenation index measured by near-infrared spectroscopy and venous jugular bulb saturation in children. Intensive Care Med 2005;31:846-50.

18. Watzman HM, Kurth CD, Montenegro LM, et al. Arterial and venous contributions to near-infrared cerebral oximetry. Anesthesiology 2000;93:947-53.

19. Chakravarti S, Srivastava S, Mittnacht AJ. Near infrared spectroscopy (NIRS) in children. Semin Cardiothorac Vasc Anesth 2008;12:70-9.

20. Kishi K, Kawaguchi M, Yoshitani K, et al. Influence of patient variables and sensor location on regional cerebral oxygen saturation measured by INVOS 4100 nearinfrared spectrophotometers. J Neurosurg Anesthesiol 2003;15:302-6.

21. Sun X, Ellis J, Corso PJ, et al. Skin pigmentation interferes with the clinical measurement of regional cerebral oxygen saturation. Br J Anaesth 2015;114:276-80.

22. Knudson JD, Neish SR, Cabrera AG, et al. Prevalence and outcomes of pediatric in-hospital cardiopulmonary resuscitation in the United States: an analysis of the Kids' Inpatient Database*. Crit Care Med 2012;40:2940-4.

23. Berg RA, Nadkarni VM, Clark AE, et al. Incidence and Outcomes of Cardiopulmonary Resuscitation in PICUs. Crit Care Med 2016;44:798-808.

24. Lowry AW, Morales DL, Graves DE, et al. Characterization of extracorporeal membrane oxygenation for pediatric cardiac arrest in the United States: analysis of the kids' inpatient database. Pediatr Cardiol 2013;34:1422-30.

25. Gupta P, Jacobs JP, Pasquali SK, et al. Epidemiology and outcomes after in-hospital cardiac arrest after pediatric cardiac surgery. Ann Thorac Surg 2014;98:2138-43; discussion 2144.

26. Rhodes JF, Blaufox AD, Seiden HS, et al. Cardiac arrest in infants after congenital heart surgery. Circulation 1999;100:II194-9.

27. Parra DA, Totapally BR, Zahn E, et al. Outcome of cardiopulmonary resuscitation in a pediatric cardiac intensive care unit. Crit Care Med 2000;28:3296-300.

28. Ortmann L, Prodhan P, Gossett J, et al. Outcomes after in-hospital cardiac arrest in children with cardiac disease: a report from Get With the Guidelines--Resuscitation. Circulation 2011;124:2329-37.

29. Endacott R, Kidd T, Chaboyer W, et al. Recognition and communication of patient deterioration in a regional hospital: a multi-methods study. Aust Crit Care
2007;20:100-5.

30. McLellan MC, Gauvreau K, Connor JA. Validation of the Cardiac Children's Hospital Early Warning Score: an early warning scoring tool to prevent cardiopulmonary arrests in children with heart disease. Congenit Heart Dis 2014;9:194-202.

31. Donchin Y, Gopher D, Olin M, et al. A look into the nature and causes of human errors in the intensive care unit. 1995. Qual Saf Health Care 2003;12:143-7; discussion 147-8.

32. Baronov D, McManus M, Butler E, et al. Next generation patient monitor powered by in-silico physiology. Conf Proc IEEE Eng Med Biol Soc 2015;2015:4447-53.

33. Tsien CL, Fackler JC. Poor prognosis for existing monitors in the intensive care unit. Crit Care Med 1997;25:614-9.

34. Chambrin MC, Ravaux P, Calvelo-Aros D, et al. Multicentric study of monitoring alarms in the adult intensive care unit (ICU): a descriptive analysis. Intensive Care Med 1999;25:1360-6.

35. Bonafide CP, Lin R, Zander M, et al. Association between exposure to nonactionable physiologic monitor alarms and response time in a children's hospital. J Hosp Med 2015;10:345-51.

36. Sendelbach S, Funk M. Alarm fatigue: a patient safety concern. AACN Adv Crit Care 2013;24:378-86; quiz 387-8.

37. Topf M, Dillon E. Noise-induced stress as a predictor of burnout in critical care nurses. Heart Lung 1988;17:567-74.

38. Laramee CB, Lesperance L, Gause D, et al. Intelligent alarm processing into clinical knowledge. Conf Proc IEEE Eng Med Biol Soc 2006;Suppl:6657-9.

39. Godin PJ, Buchman TG. Uncoupling of biological oscillators: a complementary hypothesis concerning the pathogenesis of multiple organ dysfunction syndrome. Crit Care Med 1996;24:1107-16.

40. Goldberger AL. Non-linear dynamics for clinicians: chaos theory, fractals, and complexity at the bedside. Lancet 1996;347:1312-4.

41. Makivirta A, Koski E, Kari A, et al. The median filter as a preprocessor for a patient monitor limit alarm system in intensive care. Comput Methods Programs Biomed 1991;34:139-44.

42. Imhoff $M$, Kuhls S. Alarm algorithms in critical care monitoring. Anesth Analg 2006;102:1525-37.

43. Tsien CL, Kohane IS, McIntosh N. Multiple signal integration by decision tree induction to detect artifacts in the neonatal intensive care unit. Artif Intell Med 2000;19:189-202.

44. Lambert V, Matthews A, MacDonell R, et al. Paediatric 
early warning systems for detecting and responding to clinical deterioration in children: a systematic review. BMJ Open 2017;7:e014497.

45. Smith ME, Chiovaro JC, O'Neil M, et al. Early warning system scores for clinical deterioration in hospitalized patients: a systematic review. Ann Am Thorac Soc 2014;11:1454-65.

46. Pollack MM, Holubkov R, Funai T, et al. The Pediatric Risk of Mortality Score: Update 2015. Pediatr Crit Care Med 2016;17:2-9.

47. Jeffries HE, Soto-Campos G, Katch A, et al. Pediatric Index of Cardiac Surgical Intensive Care Mortality Risk Score for Pediatric Cardiac Critical Care. Pediatr Crit Care Med 2015;16:846-52.

48. Parshuram CS, Hutchison J, Middaugh K. Development and initial validation of the Bedside Paediatric Early Warning System score. Crit Care 2009;13:R135.

49. Agulnik A, Forbes PW, Stenquist N, et al. Validation of a Pediatric Early Warning Score in Hospitalized Pediatric Oncology and Hematopoietic Stem Cell Transplant Patients. Pediatr Crit Care Med 2016;17:e146-53.

50. Pollack MM, Patel KM, Ruttimann UE. The Pediatric Risk of Mortality III--Acute Physiology Score (PRISM III-APS): a method of assessing physiologic instability for pediatric intensive care unit patients. J Pediatr 1997;131:575-81.

51. Beltempo M, Shah PS, Ye XY, et al. SNAP-II for prediction of mortality and morbidity in extremely preterm infants. J Matern Fetal Neonatal Med 2018. [Epub ahead of print].

52. Rusin CG, Acosta SI, Shekerdemian LS, et al. Prediction of imminent, severe deterioration of children with parallel circulations using real-time processing of physiologic data. J Thorac Cardiovasc Surg 2016;152:171-7.

Cite this article as: Olive MK, Owens GE. Current monitoring and innovative predictive modeling to improve care in the pediatric cardiac intensive care unit. Transl Pediatr 2018;7(2):120-128. doi: 10.21037/tp.2018.04.03
53. Fairchild KD. Predictive monitoring for early detection of sepsis in neonatal ICU patients. Curr Opin Pediatr 2013;25:172-9.

54. Griffin MP, Moorman JR. Toward the early diagnosis of neonatal sepsis and sepsis-like illness using novel heart rate analysis. Pediatrics 2001;107:97-104.

55. Moorman JR, Rusin CE, Lee H, et al. Predictive monitoring for early detection of subacute potentially catastrophic illnesses in critical care. Conf Proc IEEE Eng Med Biol Soc 2011;2011:5515-8.

56. Moorman JR, Carlo WA, Kattwinkel J, et al. Mortality reduction by heart rate characteristic monitoring in very low birth weight neonates: a randomized trial. J Pediatr 2011;159:900-6.e1.

57. Chen Y, Yang H. Heterogenous Postsurgical Data Analytics for Predictive Modeling of Mortality Risks in Intensive Care Units. Conf Proc IEEE Eng Med Biol Soc 2014:4310-4.

58. Hu SB, Wong DJ, Correa A, et al. Prediction of Clinical Deterioration in Hospitalized Adult Patients with Hematologic Malignancies Using a Neural Network Model. PLoS One 2016;11:e0161401.

59. Jalali A, Bender D, Rehman M, et al. Advanced analytics for outcome prediction in intensive care units. Conf Proc IEEE Eng Med Biol Soc 2016;2016:2520-4.

60. Jalali A, Licht DJ, Nataraj C. Application of decision tree in the prediction of periventricular leukomalacia (PVL) occurrence in neonates after heart surgery. Conf Proc IEEE Eng Med Biol Soc 2012;2012:5931-4.

61. Jalali A, Licht DJ, Nataraj C. Discovering hidden relationships in physiological signals for prediction of Periventricular Leukomalacia. Conf Proc IEEE Eng Med Biol Soc 2013;2013:7080-3. 